\title{
PROCESSOS FORMATIVOS INOVADORES NO CONTEXTO DIGITAL
}

\section{INNOVATIVE TRAINING PROCESSES IN THE DIGITAL CONTEXT}

\section{PROCESOS FORMATIVOS INNOVADORES EN EL CONTEXTO DIGITAL}

Maria Inez Pereira de Alcântara ${ }^{1}$ Ana Patricia Lima Sampaio ${ }^{2}$

Resumo: Na sociedade hodierna a preocupação com a utilização das ferramentas digitais é uma realidade em todos os setores, com maior ênfase nos ambientes educacionais, essa constatação aponta para a necessidade de maior investimento nos processos formativos dos profissionais da educação. O presente artigo é resultado de estudo realizado com profissionais do Departamento de Políticas e Programas Educacionais - DEPPE, da SEDUC. A intenção foi saber de que maneira a utilização do pacote de aplicativos da Google pode contribuir nos processos formativos. Situamos como objetivo geral analisar o desempenho dos cursistas na formação continuada onde foi apresentado as ferramentas da Google. Atribuir significado na utilização dos aplicativos às ações da gerência; dar celeridade as demandas e fomentar a mudança gradativa dos documentos analógicos para o digital foram os objetivos específicos. O procedimento metodológico utilizado foi à etnografia digital. No referencial teórico foram enfatizados conceitos pertinentes: processos formativos, aplicativos Google e aprendizagem significativa. Os resultados do estudo revelaram a importância da utilização dos aplicativos quer seja nas atividades cotidianas, ou e principalmente na ambiência dos setores educacionais nas instâncias macro (Secretaria de Educação) e micro (Unidades Escolares).

Palavras-chave: Processos Formativos. Aplicativos Google. Aprendizagem Significativa.

Abstract: In today's society, the concern with the use of digital tools is a reality in all sectors, with greater emphasis on educational environments, this finding points to the need for greater investment in the educational processes of education professionals. This article is the result of a study carried out

Submetido em: 04/11/2018 - Aceito em: 01/12/2018 - Publicado em: 26/01/2019

1 Doutora em Ciências da Educação pela Universidade Trás-os-Montes e Alto Douro (UTAD), professora efetiva da Secretaria de Educação e Qualidade do Ensino é formadora do Núcleo de Tecnologia Educacional (NTE)/CEPAN.

${ }^{2}$ Secretaria de Estado de Educação - SEDUC 


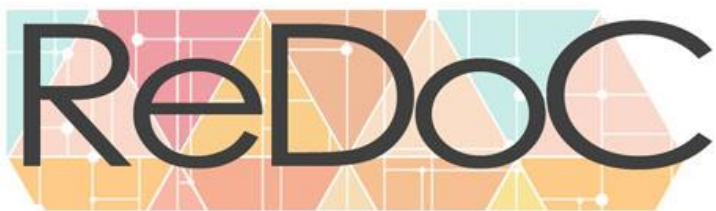

\section{Revista Docência e Cibercultura}

with professionals from the Department of Educational Policies and Programs - DEPPE, SEDUC. The intention was to know how the use of the Google application package can contribute to the training processes. We have as general objective to analyze the performance of the trainees in the continued formation where the Google tools were presented. Give meaningful use of applications to management actions; speeding up the demands and fostering the gradual shift from analogue to digital documents were the specific objectives. The methodological procedure used was digital ethnography. In the theoretical framework, relevant concepts were emphasized: formative processes, Google applications and meaningful learning. The results of the study revealed the importance of using the applications in daily activities, or mainly in the ambience of the educational sectors in the macro (Secretariat of Education) and micro (School Units) instances.

Keywords: Formative processes. Google applications. Significant Learning.

\section{INTRODUÇÃO}

Apresentamos nesse artigo, um estudo sobre processos formativos com Profissionais da Educação que exercem atividades pedagógicas no Departamento de Políticas e Programas Educacionais (DEPPE), da Secretaria de Estado de Educação (SEDUC).

A pretensão foi saber de que maneira a utilização do pacote de aplicativos Google pode contribuir nos processos formativos dos profissionais da educação. Situamos como objetivo geral analisar o desempenho dos cursistas na formação continuada onde foram apresentados os aplicativos da Google.

Atribuir significado na utilização dos aplicativos Google Forms e Docs às ações da gerência; dar celeridade as demandas das gerências da secretaria e fomentar a mudança gradativa dos documentos da gerência do analógico para o digital foram os objetivos específicos.

Para o alcance dos objetivos estabelecemos o percurso metodológico da experiência baseado na Etnografia digital.

\section{PROCESSOS FORMATIVOS E A LEGISLAÇÃO}

Processos formativos são temas recorrentes em pesquisas que buscam revelar a aprendizagem dos profissionais da educação, professores, pedagogos, e gestores, atuantes em sala de aula e aqueles 


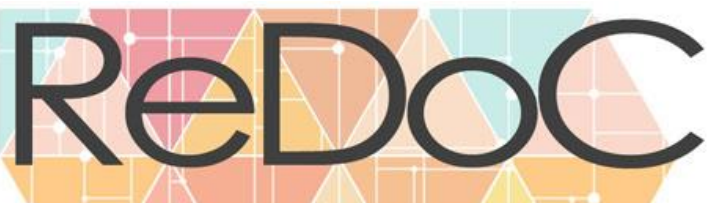

\section{Revista Docência e Cibercultura}

que desenvolvem atividades em outras instâncias educativas tais como gerências e setores em Secretarias de Educação em nível macro.

O aprendizado da docência é um processo contínuo, que se dá ao longo da vida profissional, articulado às práticas e ao contexto da atividade dos professores (ANDRÉ, 2010). Por tanto, entender de que maneira os processos formativos corroboram para a formação continuada desses profissionais configura-se de extrema importância, uma vez que o aprendizado acumulado durante a sua trajetória irá influenciar diretamente no fazer docente dos mesmos.

Ao considerar os processos formativos na sociedade contemporânea, na qual a tecnologia digital é uma realidade circundante e desafiadora para todos os cidadãos, é necessário repensar os modos de comunicar, de ensinar e de aprender, afim de, alinhar as formações com a nova realidade, inclusive as diretrizes dispostas nos mecanismos legais.

Neste sentido, a Lei de Diretrizes e Bases da Educação Nacional de 1996 (LDBEN) em consonância com a Constituição Brasileira de 1988, dedica um capítulo específico à formação dos profissionais da educação, com destaque para os professores. É retratado no Art. 61. "A formação de profissionais da educação, de modo a atender aos objetivos dos diferentes níveis e modalidades de ensino e as características de cada fase do desenvolvimento do educando, terá como fundamentos: I a associação entre teorias e práticas, inclusive mediante a capacitação em serviço; II aproveitamento da formação e experiências anteriores em instituições de ensino e outras atividades".

O Art. 62 destaca: “A formação de docentes para atuar na educação básica far-se-á em nível superior, em curso de licenciatura, de graduação plena, em universidades e institutos superiores de educação, admitida, como formação mínima para o exercício do magistério na educação infantil e nas quatro primeiras séries do ensino fundamental, a oferecida em nível médio, na modalidade Normal".

No Art. 63, está descrito que "Os institutos superiores de educação manterão: I - cursos formadores de profissionais para a educação básica, inclusive o curso normal superior, destinado à formação de docentes para a educação infantil e para as primeiras séries do ensino fundamental; II programas de formação pedagógica para portadores de diplomas de educação superior que queiram se dedicar à educação básica; III - programas de educação continuada para os profissionais de educação dos diversos níveis". 


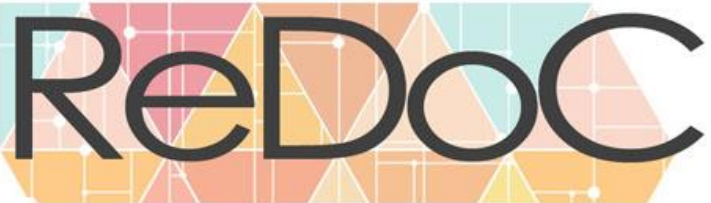

\section{Revista Docência e Cibercultura}

Os programas de educação continuada estão assegurados pelo decreto $\mathrm{N}^{\circ} 8.752$, de 9 de maio de 2016 que dispõe sobre a Política Nacional de Formação dos Profissionais da Educação Básica e a Portaria N ${ }^{\circ} 1.328$, de 23 de setembro de 2011 que institui a Rede Nacional de Formação Continuada dos profissionais do Magistério da Educação Básica Pública.

Outro documento legal em vigência refere-se ao Plano Nacional de Educação (PNE) instituído pela Lei $N^{o} 13.005 / 2014$, em vigor desde o ano de sua promulgação com prazo de dez anos para ser implantado, possui 20 metas estruturantes determinadas pelo governo federal para garantir o direito à educação de qualidade. A Meta 16 do PNE refere-se à formação continuada dos profissionais da educação a qual destaca: “formar, em nível de pós-graduação, 50\% dos professores da Educação Básica, até o último ano de vigência deste PNE, e garantir a todos os (as) profissionais da Educação Básica formação continuada em sua área de atuação, considerando as necessidades, demandas e contextualizações dos sistemas de ensino".

Baseado nos dispositivos legais e, sobretudo na preocupação decorrente aos desafios dos profissionais da educação quanto à utilização dos aparatos tecnológicos na escola, foi realizada uma formação continuada envolvendo as instâncias macro da Secretaria de Estado de Educação-SEDUC, no caso particular o Departamento de Políticas e Programas Educacionais - DEPPE.

\section{A GUISA DE CONTEXTUALIZAÇÃO DA EXPERIÊNCIA}

O Departamento de Políticas e Programas Educacionais é responsável pela implementação e desenvolvimento de políticas de educação no estado.

Ao DEPP compete, entre outros fins na estrutura organizacional da Secretaria de Estado de Educação e Qualidade do Ensino (SEDUC), planejar, orientar, coordenar, acompanhar e supervisionar o processo de formulação e implementação das políticas para a educação básica - ensino fundamental e ensino médio: alfabetização, educação de jovens e adultos, educação em direitos humanos, educação especial, educação do campo, educação escolar indígena, educação quilombola e educação para as relações étnico-raciais; promover ações de fortalecimento, expansão e a melhoria da qualidade da educação; contribuir para o desenvolvimento inclusivo voltado à valorização das diferenças e da diversidade, a promoção da educação inclusiva, dos direitos humanos e da sustentabilidade 


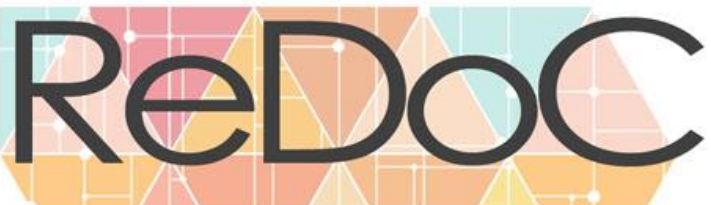

\section{Revista Docência e Cibercultura}

socioambiental visando à melhoria de políticas públicas transversais na rede estadual de ensino do Amazonas. (Fonte) $)^{3}$.

Integra esse departamento a Gerência do Ensino Fundamental - GENF; Gerência do Ensino Médio - GEM; Gerência de Atendimento Educacional à Diversidade - GAED, Gerência de Atendimento Educacional Específico - GAEE e Gerência de Educação Escolar Indígena - GEEI.

Em face das competências do Departamento conhecer e trabalhar com os aplicativos digitais, é de extrema relevância, sobretudo pela celeridade nas ações e conectividade proporcionadas a todos envolvidas no gerenciamento do processo educativo.

\section{APLICATIVOS GRATUITOS DIGITAIS E SEU POTENCIAL PEDAGÓGICO}

O uso inteligente das ferramentas digitais foi denominado por Alcântara, Escola e Oliveira (2017) por comunicação educativa. Usar com criticidade tais ferramentas requer do usuário uma postura inteligente para selecionar aquelas das outras.

No âmbito educacional, a utilização dos aparatos tecnológicos em sala de aula, tais como os aplicativos gratuitos disponibilizados na $W e b$, exige dos profissionais um posicionamento crítico quanto à escolha, sendo assim é importante analisar o potencial pedagógico de cada pacote de aplicativos.

A experiência ora relatada foi realizada no ateliê pedagógico constituído por 06 (seis) aplicativos: Google Documentos, para a edição colaborativa de textos; Google Spreadsheets, para a edição colaborativa de planilhas eletrônicas; Google Forms, para a confecção de formulários online; Google Presentations, para a edição colaborativa de apresentações de slides e Google Drawings, para a edição colaborativa de desenhos, Sampaio e Alcântara (2018) e Google Classroom (Sala de aula) é um ambiente virtual de aprendizagem (AVA), que possibilita a organização de turmas e

3 Portal do Governo do Estado do Amazonas. Disponível em:
http://www.educacao.am.gov.br/institucional/estrutura/deppe/. 


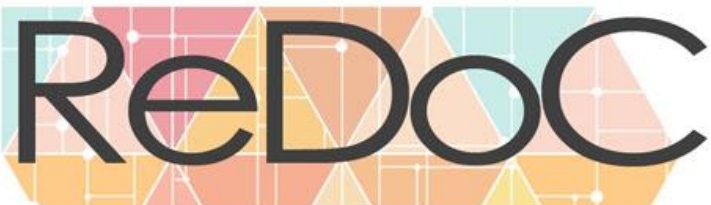

\section{Revista Docência e Cibercultura}

direcionamento de trabalhos pedagógicos usando ou não as demais ferramentas Google Apps. Schiehl e Gasparini (2016).

Dos aplicativos gratuitos da Google, priorizaram-se Documentos, Formulários, e Classroom, haja vista serem os mais significativos para os cursistas considerando as características das atividades desenvolvidas por eles estarem conectadas ao processo pedagógico, no que tange ao acompanhamento das escolas sob a jurisdição do DEPEE.

Todavia, é importante ressaltar que para o enfrentamento das dificuldades, faz-se necessário um agir crítico e significativo sobre a utilização dos dispositivos digitais tecnológicos nos diferentes setores da sociedade da informação, a fim de proporcionar a aprendizagem significativa.

\section{A APRENDIZAGEM SIGNIFICATIVA DOS DISPOSITIVOS DIGITAIS TECNOLÓGICOS}

Aprendizagem significativa é uma proposta de aprendizagem defendida em sua gênese por Ausubel, no início da década de 60. Nela o autor reforça que a aprendizagem é significativa quando um novo conhecimento encontra suporte num conhecimento anterior. Assim, a nova informação é agregada à estrutura conceitual específica do sujeito, denominada por Ausubel (2003) de conceito "subsunçor".

Nesse caso, quando isso acontece, a aprendizagem se processa com maior presteza. Nada obstante o contrário é verdadeiro, ou seja, quando o novo conhecimento não encontra aporte na estrutura cognitivas do aprendiz, a aprendizagem passa a ser puramente mecanizada, focada na memorização. Assim sendo, é extremamente relevante à valorização dos conhecimentos prévios construídos historicamente pelos estudantes e na mesma ordem de relevância está o conhecimento docente sobre esse aspecto.

Atualmente um dos grandes desafios recorrentes na sociedade, sobretudo na escola é a presença maciça dos dispositivos digitais tecnológicos.

Na escola, pondera Ribeiro, (2005) os sistemas acadêmicos de frequência e notas já são, em grande medida, digitais, o que alterou nossos tempos e modos de trabalho. Parte dos materiais de que dispomos para planejar e ministrar nossas aulas pode ser de tecnologia digital, assim como muitos dos 


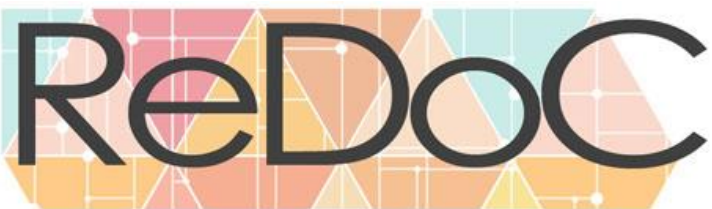

\section{Revista Docência e Cibercultura}

meios de que dispomos para interagir com nossos alunos. No entanto, considerar a tecnologia digital, desde a alfabetização, exige que incorporemos esta cultura nos materiais e nas práticas cotidianas com crianças, seja produzindo registros imagéticos e verbais, seja usando jogos para aprender, seja lendo e escrevendo em dispositivos digitais, como teclado de grandes computadores ou de um celular. Implica, além de tudo, saber que crianças que já nasceram inseridas nessa cultura passam a pensar e agir com esses dispositivos, quer a escola queira ou não.

Deste modo, incorporar a cultura digital e seus diferentes aplicativos nas práticas do dia a dia, sobretudo, no ambiente escolar, pressupõe reconhecimento das gerações que nasceram na era digital, as quais Prenski (2001) denomina de nativos digitais, reconhecer e compreender como os nativos aprendem e agem no contexto digital, é o desafio a ser vencido pelos educadores imigrantes digitais Prenski (2001).

Sendo assim, é necessário um maior investimento na formação continuada dos profissionais da educação, no sentido de ultrapassar os desafios impostos pela presença maciça dos aplicativos digitais.

\section{METODOLOGIA}

Metodologia é um caminho a ser percorrido para se chegar a um fim determinado. Todavia, nesse percurso, convém considerar as características do público alvo, os conhecimentos prévios destes, os objetivos e os recursos disponíveis.

Nesse sentido a metodologia utilizada foi à etnografia digital Reis (2011) em virtude de proporcionar estudo observatório-interativo, que tem como objetivo entender o comportamento do consumidor na $W e b$, observando sua navegação, interagindo com ele enquanto está online e coletando informações sobre sua relação com o ambiente digital, de forma a entender que tipo de mudanças essa inclusão digital provoca nos usuários da Internet. Essa metodologia introduz uma inovação na pesquisa online, na medida em que o objeto de estudo é o ambiente online em si, tendo como foco o dia a dia das pessoas na Internet, o uso que fazem do meio e como se relacionam com esse mundo virtual.

A etnografia digital, ou etnografia, de acordo com Hine (2000) apud Reis (2011), analisa as práticas sociais na internet e o sentido destas para os participantes. Por meio dela é possível estudar relações nos espaços virtuais, neste caso em particular, nos ambientes virtuais de aprendizagem. 


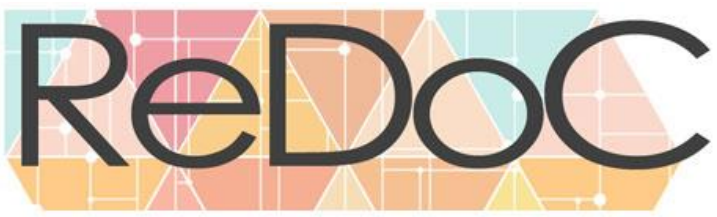

\section{Revista Docência e Cibercultura}

O público alvo a participar do ateliê foi um contingente de 10 (dez) participantes, e carga horária de 15h, distribuída em 04 (quatro) aulas, realizada no laboratório de informática. Foram trabalhados os aplicativos: Docs, Forms e Classroom, esse último foi realizado no Ambiente Virtual de Aprendizagem da Google.

\section{RESULTADOS E DISCUSSÕES}

Durante o ateliê pedagógico foi solicitado aos participantes à criação de documentos, formulários utilizados nas atividades rotineiras do departamento, atribuindo dessa forma significado aos mesmos. As telas das figuras 1 e 2 são resultados das atividades realizadas pelos participantes.

Produção dos cursistas Google Docs e Forms

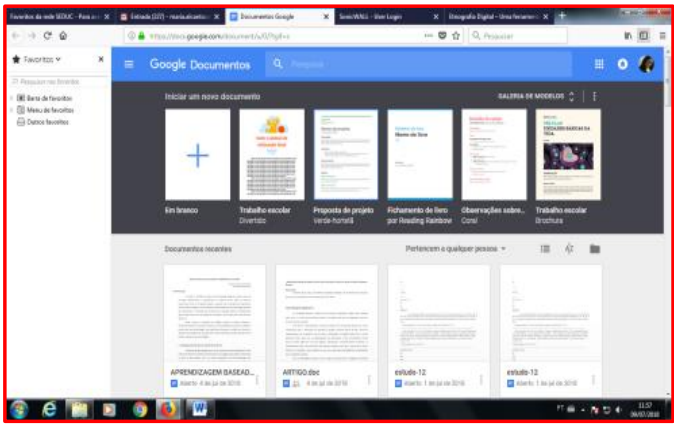

Figura 1: Captura da tela dos recursos Google Docs

Fonte: elaborado pelas autoras (2017)

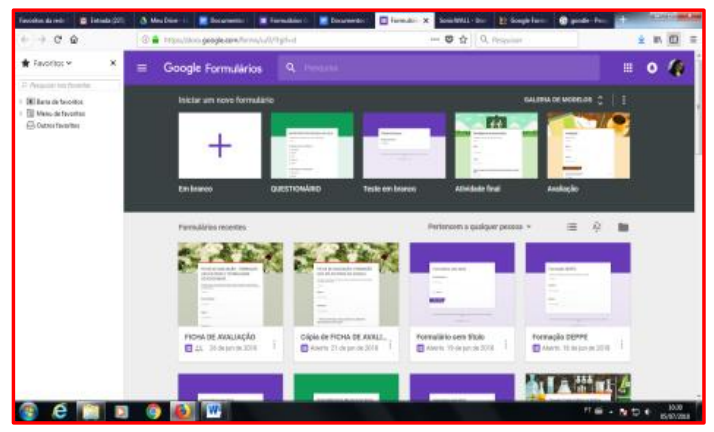

Figura 2: Captura da tela dos recursos Google Forms

Fonte: elaborado pelas autoras (2017)

Quanto ao aplicativo Google Classroom, cada um dos participantes criou sua própria sala de aula virtual, além disso, disponibilizaram material de acordo com as características de cada sala. 


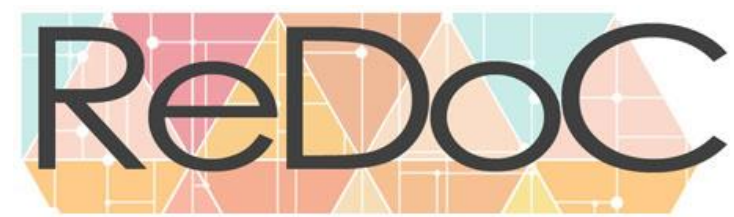

Revista Docência e Cibercultura

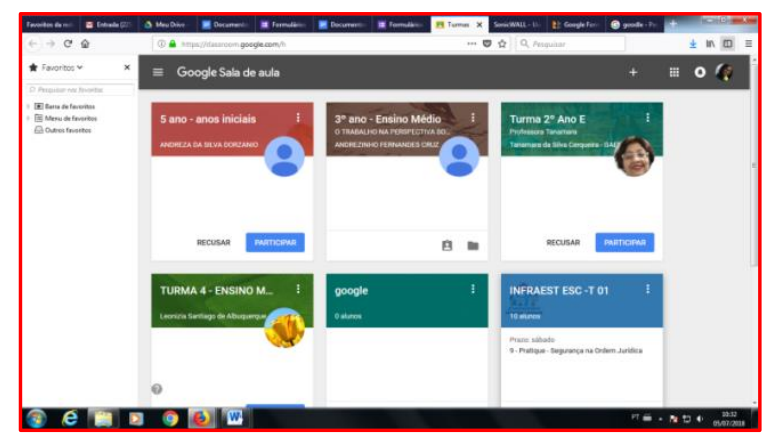

Figura 3: Captura da tela dos recursos Classroom Fonte: elaborado pelas autoras (2017)

$\mathrm{Na}$ tentativa de buscar informações que nos fornecessem um feedback sobre a formação, elaboramos um formulário com 07 (sete) questões, sendo 04 (quatro) de múltipla escolha e 01 (uma) resposta curta e 02 (duas) texto. Posteriormente o formulário foi compartilhado entre os cursistas.

Nesta atividade, tivemos oportunidade de trabalhar alguns tipos de respostas tais como: resposta curta, texto e múltipla escolha, além da apresentação das respostas em gráficos.

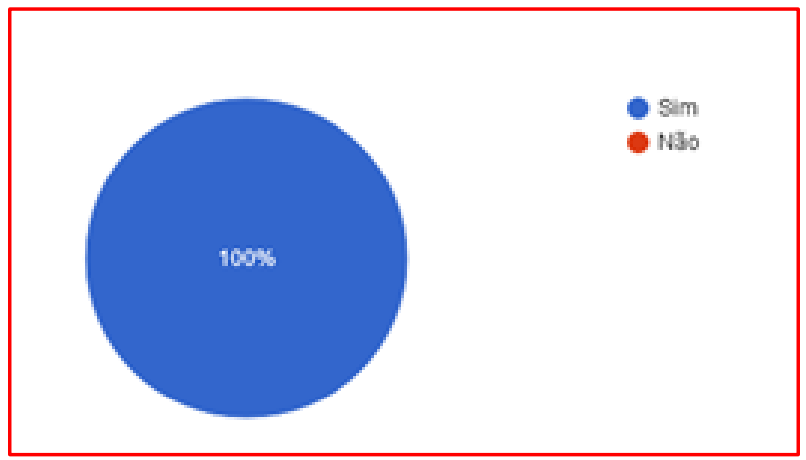

Gráfico 1: Corresponde a primeira questão do questionário aplicado aos 10 participantes

Fonte: elaborado pelas autoras (2017)

A gráfico 1 revela que os respondentes, já utilizavam alguns aplicativos, a imagem abaixo aponta os mais usados. Esta constatação demonstra já possuírem habilidades no uso desses recursos. $\mathrm{Na}$ perspectiva de Ausubel (2002) possuem subsunçores ou ideia âncora para aportar novos conhecimentos, esta constatação reverte de significado às atividades propostas no ateliê. 
Revista Docência e Cibercultura

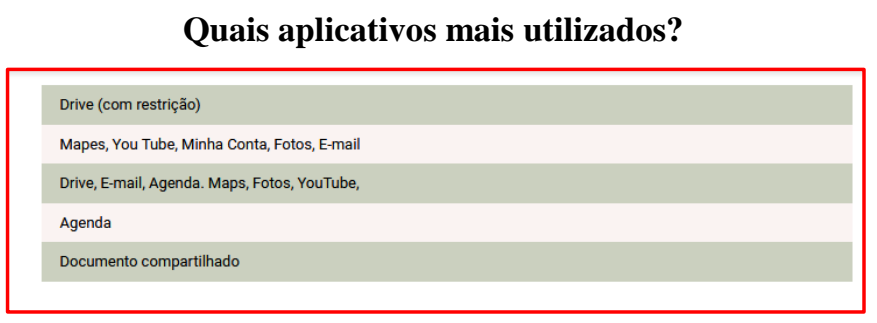

Figura 4: Captura de tela com as respostas quanto aos aplicativos utilizados pelos respondentes

Fonte: elaborado pelas autoras (2017)

A figura 4 corresponde aos aplicativos utilizados pelos cursistas antes do ateliê. As respostas apresentadas revelam que os mais utilizados correspondem às redes sociais virtuais, todavia são conhecimentos prévios que facilitaram o entendimento dos novos aplicativos. A pergunta 2 refere-se ao tempo destinado a realização do ateliê.

Em relação ao tempo para realização do ateliê, você considerou?

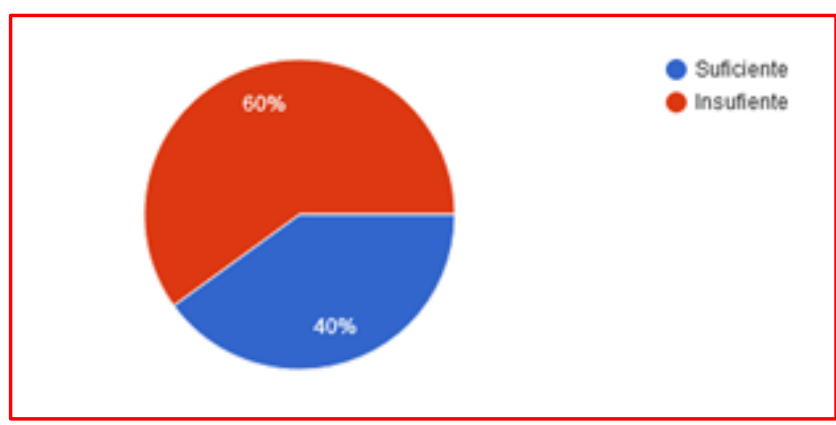

Gráfico 2: Refere-se ao tempo destinado à realização do Ateliê Pedagógico

Fonte: elaborado pelas autoras (2017)

O gráfico 2 destaca que para $40 \%$ dos participantes o tempo foi suficiente, podemos atribuir esse resultado as habilidades destes quanto ao uso dos aplicativos ou a categoria de nativos digitais conceituados por Prenski (2001) quando se refere a pessoas que já nasceram no contexto da cultura digital, convivendo e explorando cotidianamente tais dispositivos. Outra categoria é geração digital, grupo de pessoas nascida no contexto da cultura digital (FALCÃO, MILL, 2018).Todavia, 60\% dos participantes considera o tempo insuficiente, esse resultado pode ser em virtude dos participantes terem 


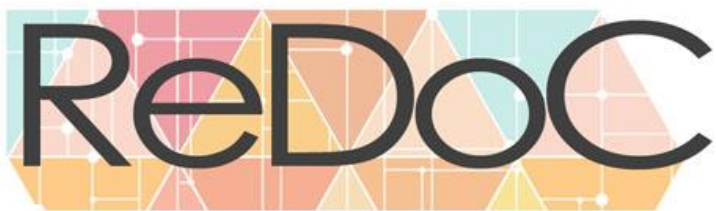

\section{Revista Docência e Cibercultura}

limitações quanto ao uso dos aplicativos, são os imigrantes digitais na perspectiva de Prenski (2001 apud FALCÃO, MILL, 2018), para o autor essa categoria refere-se as pessoas que nasceram antes dos anos de 1990 antes da popularização do videogame, do computador, da internet e de seus dispositivos.

Como você considera o seu desempenho?

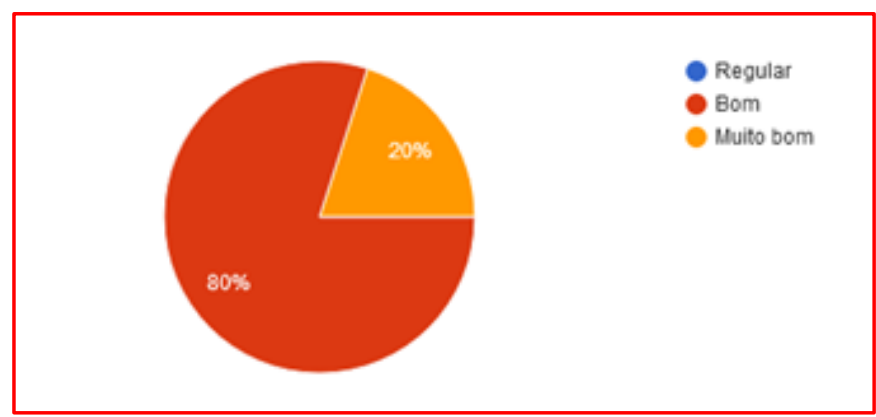

Gráfico 3: Auto avaliação do desempenho dos participantes Fonte: elaborado pelas autoras (2017)

O gráfico 3 mostra que $80 \%$ dos respondentes consideraram o desempenho bom. Não obstante, $100 \%$ responderam que já utilizavam os aplicativos (ver figura 1) percebe-se uma incompatibilidade nas respostas. Outra constatação é que não houve respondentes com desempenho regular.

Desta feita, Luckesi (2002) distingue a avaliação como uma forma de ajuizamento da qualidade do objeto avaliado, fator que implica uma tomada de posição a respeito do mesmo, para aceitá-lo ou para transformá-lo. A avaliação é um julgamento de valor sobre manifestações relevantes da realidade, tenso em vista uma tomada de decisão.

A avaliação de desempenho refere-se a um mecanismo ou ferramenta que busca conhecer e medir o desempenho dos indivíduos na organização, estabelecendo uma comparação entre o desempenho esperado e o apresentado por esses indivíduos. Nesse sentido, apesar da incompatibilidade das respostas, os cursistas respondentes se auto avaliaram com o desempenho bom, o que evidencia que os objetivos da formação foram alcançados. 

formaçấ, considerou:

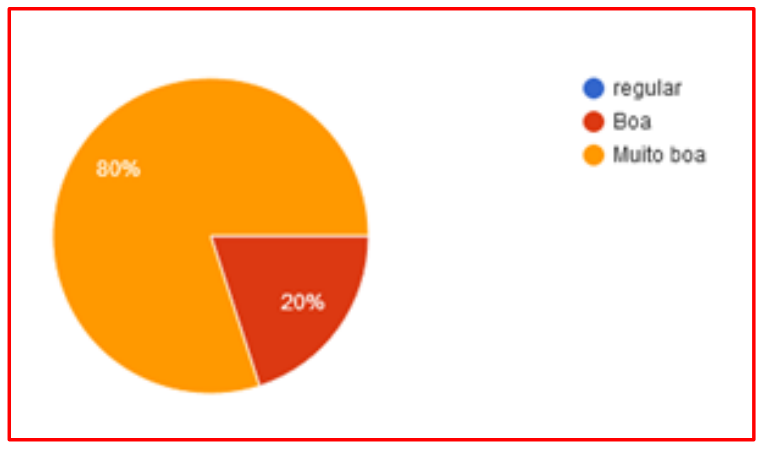

Gráfico 4: Metodologia da formação

Fonte: elaborado pelas autoras (2017)

O gráfico 3 aponta que a metodologia aplicada foi considerada por $80 \%$ dos respondentes como muito boa, entretanto os $20 \%$ chama atenção para uma necessidade de reflexão sobre os procedimentos metodológicos a fim de reestruturá-los para alcançar a totalidade dos participantes. Tal necessidade desponta como uma das finalidades da avaliação que é o feedback, que permite tomada de decisão.

\section{Dos aplicativos trabalhados, qual ou quais poderão ser utilizados na sua gerência?}

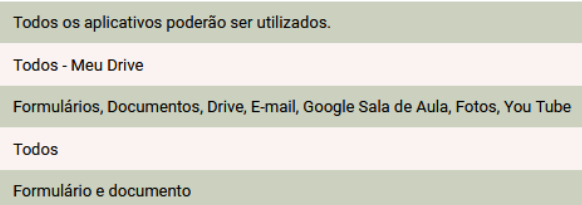

Figura 5: Captura de tela com as respostas quanto aos aplicativos que podem ser usados nas gerências

Fonte: elaborado pelas autoras (2017)

A figura 5 diz respeito aos recursos trabalhados no percurso da formação e que poderão ser utilizados no ambiente de trabalho dos respondentes, das cinco respostas, três afirmaram que todos os aplicativos podem ser utilizados, logo essa constatação assinala a necessidade de um investimento maior na formação continuada do profissional da educação na direção da aprendizagem móvel.

Aprendizagem móvel é definida por pesquisadores, como Tarouco (2004), Traxler (2007) e Moura (2009) apud Boll, Ramos e Real (2018) como aquela que, com o apoio de tecnologias e dispositivos móveis, integra-se à portabilidade técnica, convergindo-a com as diferentes mídias e com 


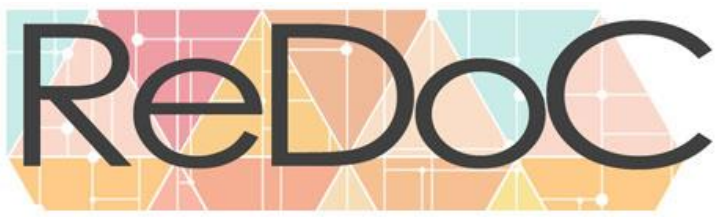

\section{Revista Docência e Cibercultura}

a flexibilidade e condições dos alunos, localizados física e/ou geograficamente distantes, incluindo as variadas formas de acessibilidade oferecidas.

O trabalho com os recursos da Google abre um leque de possiblidades para o desenvolvimento de textos coletivos, compartilhamento de informações, vídeos e imagens entre outros, independente da presença física de seus usuários.

Dos aplicativos trabalhados, qual ou quais você começou a utilizar a partir da formação Aplicativos e Tecnologias Educacionais?

\begin{tabular}{|l|}
\hline Formulários e documentos. \\
\hline Meu Drive - Google \\
\hline Formulários, Documentos, os outros já utilizo \\
\hline $\begin{array}{l}\text { Ainda não foram aplicados. No entanto, o aplicativo "Documentos" poderá ser bastante utilizado em alguma Ação } \\
\text { que eu venha executar. }\end{array}$ \\
$\begin{array}{l}\text { Minha avaliação se restringe apenas a primeira aula, em função de não ter concluido a formação pela demanda de } \\
\text { trabalho no periodo. } \\
\text { A escolha dos aplicativos que poderão ser usados na gerência ficaram restritos ao que conheço }\end{array}$ \\
\hline
\end{tabular}

Figura 6: Captura de tela com as respostas sobre uso dos aplicativos no trabalho, após a formação

Fonte: elaborado pelas autoras (2017)

A figura 6 diz respeito aos aplicativos que passaram a ser utilizados após a formação. As respostas destacam que Google Docs, Forms e Drive estão sendo os mais empregados, o que comprova que a aprendizagem foi significativa.

Aprendizagem significativa é aquela em que ideias expressas simbolicamente interagem de maneira substantiva e não arbitrária com aquilo que o aprendiz já sabe. Substantiva quer dizer nãoliteral, não ao pé-da-letra, e não-arbitrária significa que a interação não é com qualquer ideia prévia, mas sim com algum conhecimento especificamente relevante já existente na estrutura cognitiva do sujeito que aprende. Moreira (2012).

Portanto, partimos do pressuposto que os respondentes já possuíam conhecimento relevante nas suas estruturas cognitivas sobre os aplicativos esse episódio harmonizou o aprendizado e a aplicabilidade do pacote de aplicativos da Google com propriedade.

\section{CONSIDERAÇÕES FINAIS}




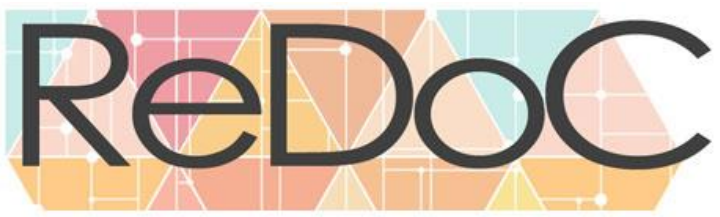

\section{Revista Docência e Cibercultura}

Os processos formativos inovadores no contexto digital, título da experiência ora relatada apontou a importância da formação voltada para os profissionais de ensino nas instâncias macro da Secretaria de Educação, mostrando que não basta conhecer os aplicativos é necessário, sobretudo sua utilização de maneira inteligente e crítica.

Viver na sociedade atual impõe a necessidade de perceber os aparatos tecnológicos como aliados no desenvolvimento de atividades cotidianas e nomeadamente nos ambientes escolares. Trazer o pacote dos aplicativos da Google para os departamentos e gerências da Secretaria, é uma possibilidade de dar celeridade à atividade desenvolve habilidades de compartilhamento, de integração social virtual entre outras.

\section{REFERÊNCIAS BIBLIOGRÁFICAS}

ALCÂNTARA, Maria Inez Pereira de et al. Comunicação educativa no ensino de ciências naturais na educação infantil: um estudo no curso de formação inicial de professores. 2017.

ANDRÉ, Marli. Formação de professores: a constituição de um campo de estudos. Educação, Porto Alegre, v. 33, n. 3, p. 174-181, set./dez. 2010.

AUSUBEL, David. Aquisição e retenção de conhecimentos: Uma perspectiva cognitiva, Lisboa: Editora Plátano, 2003.

BOLL, C. I; RAMOS, W. M.; REAL, L. C. Tecnologia Móvel. In: MILL, Daniel (Org). Dicionário Crítico de Educação e Tecnologias e de Educação a Distância. Editora: Papirus (Campinas), 2018.

BRASIL. Constituição da República Federativa do Brasil. Promulgada em 5 de outubro de 1988. Brasília, 1988.

Lei de Diretrizes e Bases da Educação Nacional (LDBEN). Lei nº 9.394, de 20 de dezembro de 1996.

Base Nacional Comum Curricular. Versão final. MEC, 2017. Disponível em: $<$ http://portal.mec.gov.br/index.php?option=com_docman\&view=download\&alias=79601-anexotexto-bncc-reexportado-pdf-2\&category_slug=dezembro-2017-pdf\&Itemid=30192>. Acesso em: 10 de setembro de 2018. 


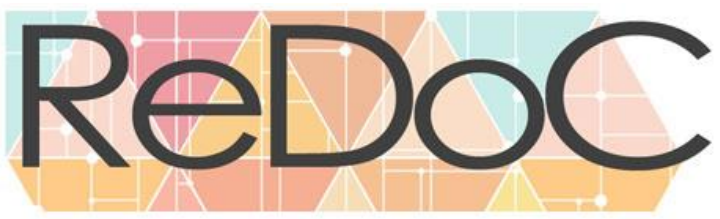

\section{Revista Docência e Cibercultura}

Decreto n. 8.752, de 09 de maio de 2016 (2016). Dispõe sobre a Política Nacional de Formação dos Profissionais da Educação Básica. Brasília, DF. Disponível em: http://www.planalto.gov.br/ccivil 03/ Ato2015-2018/2016/. Acesso em: 02 de agosto de 2018.

Lei n. 13.005, de 25 de junho de 2014 (2014). Aprova o Plano Nacional de Educação - PNE e dá outras providências. Brasília, DF. Disponível em: https://www.planalto.gov.br/ccivil 03/ ato20112014/2014/lei/l13005.htm. Acesso em: 02 de agosto de 2018.

PORTARIA MEC N 1.328, DE 23 DE SETEMBRO DE 2011. Disponível em: http://portal.mec.gov.br/index.php?option=com docman\&view=download\&alias=10039-portaria-1328-2309-2011\&category slug=fevereiro-2012-pdf\&ltemid=30192. Acesso em: 16 de agosto de 2018.

FALCÃO, Patrícia Mirella; DANIEL, Mill. INFÂNCIA E TECNOLOGIAS DIGITAIS NA ESCOLA. CIET: EnPED, 2018. Disponível em: https://scholar.google.com.br/scholar?hl=ptBR\&as_sdt $=0 \% 2 \mathrm{C} 5 \&$ scioq $=$ Ausubel+\%282002\%29+de+conceito+\%E2\%80\%9Csubsun\%C3\%A7o $\mathrm{r} \& \mathrm{q}=\mathrm{MILL} \% 2 \mathrm{C}+\mathrm{OLIVEIRA} \% 2 \mathrm{C}+\mathrm{FALC} \% \mathrm{C} 3 \% 83 \mathrm{O} \% 2 \mathrm{C}+2018 \& \mathrm{btnG}$. Acesso em: 12 de setembro de 2018.

LUCKESI, Cipriano C. Avaliação da aprendizagem escolar. 13º ed. São Paulo: Cortez, 2002.

MATHIAS, Sergio Larruscaim; SAKAI, Celio. Utilização da Ferramenta Google Forms no Processo de Avaliação Institucional: Estudo de Caso nas Faculdades Magsul. Disponível em: <http://download.inep.gov.br/educacao superior/avaliacao institucional/seminarios regionais/trabalhos $r$ egiao/2013/centro oeste/eixo 1/google forms processo avaliacao instit estudo caso faculdades mag.p df $>$. Acesso em: 03 de julho de 2018.

MOREIRA, Marco Antonio. O que é afinal aprendizagem significativa? Aula Inaugural do Programa de Pós-Graduação em Ensino de Ciências Naturais, Instituto de Física, Universidade Federal do Mato Grosso, Cuiabá, MT, 23 de abril de 2010. Aceito para publicação, Curriculum, La Laguna, Espanha, 2012. Disponível em: 〈http://moreira.if.ufrgs.br/oqueeafinal.pdf>. Acesso em: 16 de agosto de 2018.

PRENSKY, M. Digital Native, digital immigrants. Digital Native immigrants. On the horizon, MCB University Press, Vol. 9, N.5, October, 2001. Acesso em: 03 de junho de 2018. Disponível em: $<$ http://www.marcprensky.com/writing/Prensky\%20-\%20Digital\%20Natives,\%20Digital $\%$ 20Immigrants\%20-\%20Part1.pdf $>$. 


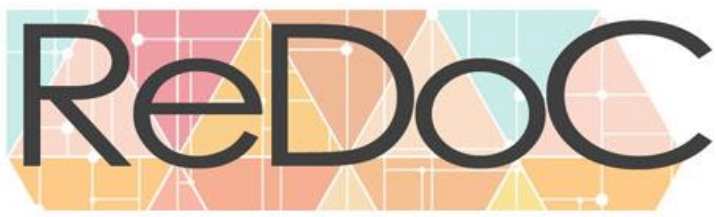

Revista Docência e Cibercultura

Stephen et al. Recent developments in logging technology. Petrophysics, v. 43, n. 03, 2002.

REIS, Ana Helena Meirelle. Etnografia Digital Uma ferramenta essencial para conhecer o usuário de internet. Multifocos, 2011. Disponível em: 〈http://www.multifocus.com.br/blog/etnografiadigital-uma-ferramenta-essencial-para-conhecer-o-usuario-de-internet>. Acesso em: 09 de julho de 2018.

RIBEIRO, Ana Elisa. Ler na tela-letramento e novos suportes de leitura e escrita. Letramento digital: aspectos sociais e possibilidades pedagógicas. Belo Horizonte: Ceale, p. 125-149, 2005. Disponível em: <http://www.ceale.fae.ufmg.br/app/webroot/glossarioceale/verbetes/tecnologia-digital>. Acesso em: 29 de junho de 2018.

SAMPAIO, Ana Patrícia Lima; DE ALCÂNTARA, Maria Inez Pereira. Upgrade na interface do formulário online da Google: ambiente colaborativo de aprendizagem. Revista Docência e Cibercultura, v. 2, n. 2, p. 51-67.

SCHIEHL, Edson Pedro; GASPARINI, Isabela. Contribuições do Google Sala de Aula para o Ensino Híbrido. RENOTE, v. 14, n. 2, 2016. 